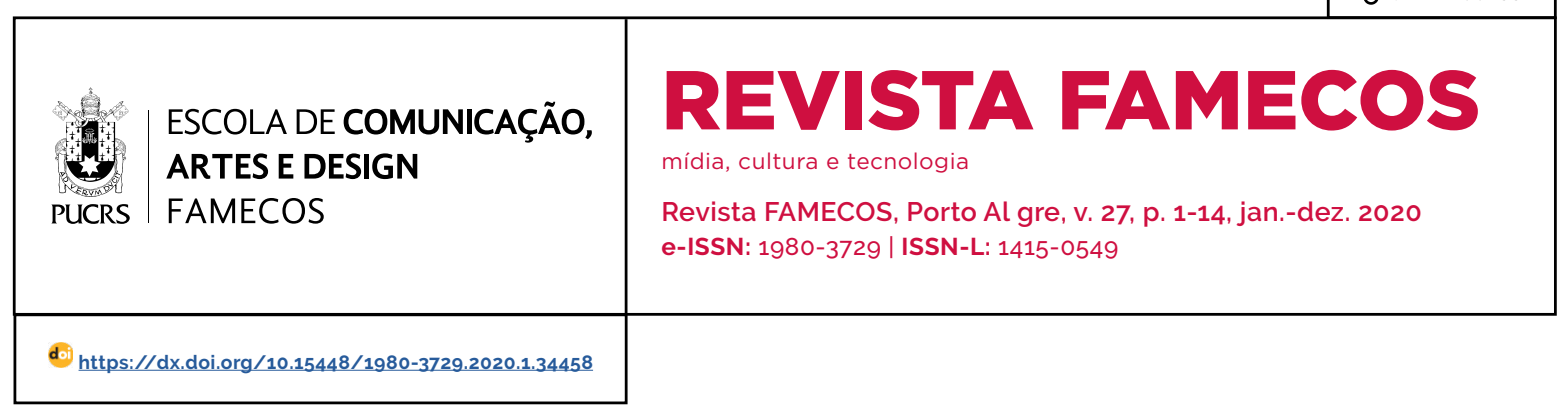

MÍDIA E CULTURA

\title{
Adolescentes, televisão e ciência: um estudo exploratório a partir da publicidade brasileira
}

\author{
Adolescents, television and science: an exploratory study from brazilian advertising \\ Adolescentes, televisión y ciencia: un estudio exploratorio a partir de la publicidade brasileña
}

\section{Vanessa Brasil de Carvalho ${ }^{1}$ orcid.org/0000-0001-6891-9919 vanessabrasilcarvalho@gmail.com}

\section{Luisa Massarani ${ }^{1}$}

orcid.org/0000-0002-5710-7242 luisa.massarani6@gmail.com

Recebido em: 12 jun. 2019. Aprovado em: 22 ago. 2019. Publicado em: 16 jul. 2020.
Resumo: Este artigo apresenta uma análise qualitativa na intersecção entre os campos da divulgação científica e comunicação, trazendo reflexões sobre a percepção pública da ciência de adolescentes brasileiros identificada a partir de publicidades televisivas. Por meio de entrevistas, buscamos entender de que forma esses jovens entendem e se relacionam com os conteúdos científicos presentes nessas programações televisivas que, tão recorrentemente, fazem uso de tais conteúdos como um recurso motivador de compra. Os entrevistados se mostraram bastante críticos à programação televisiva, evidenciando que constroem diversos sentidos a partir dela. Embora os resultados não sejam conclusivos ou exaustivos, em virtude do caráter qualitativo desta pesquisa, percebemos que é possivel que a percepção dos jovens sobre o conceito de ciência possa estar ligada à abordagem desses assuntos em publicidades.

Palavras chaves: Percepção pública da ciência. Adolescentes. Publicidades.

Abstract: This paper shows a qualitative analysis at the intersection between scientific communication and communication, bringing reflections of Brazilian teenagers' public perception of science generated by television advertising. Through interviews, we seek to understand how these young people understand and relate to the scientific content present in these kind of advertising that, so recurrently, make use of such content as a purchase motivator. The interviewees were very critical on television advertising, showing that they construct several meanings from it. Although the results are not conclusive or exhaustive, due to the qualitative nature of this research, we realize that it's possible that the perception of the young people about Science can be linked to the approach of these subjects in advertisements.

Keywords: Public understanding of Science. Teenagers. Advertising

Resumen: Este artículo presenta un análisis cualitativo en la intersección entre los campos de la divulgación científica y comunicación, trayendo reflexiones sobre la percepción pública de la ciencia de adolescentes brasileños identificada a partir de publicidades televisivas. Por medio de entrevistas, buscamos entender de qué forma esos jóvenes entienden y se relacionan con los contenidos científicos presentes en esas programaciones televisivas que, tan recurrentemente, hacen uso de tales contenidos como un recurso motivador de compra. Los entrevistados se mostraron bastantes críticos a la programación televisiva, evidenciando que construyen diversos sentidos a partir de ella. Aunque los resultados no son concluyentes o exhaustivos, en virtud del carácter cualitativo de esta investigación, percibimos que es posible que la percepción de los jóvenes sobre el concepto de ciencia pueda estar ligada al abordaje de esos asuntos en las publicidades. Palabras claves: Percepción pública de la ciência. Adolescentes. Publicidad.

\section{(c) (i)}

Artigo está licenciado sob forma de uma licença Creative Commons Atribuição 4.0 Internacional. 


\section{Introdução}

A enquete mais recente sobre a percepção pública de ciência e tecnologia (C\&T) no Brasil indicou que pouco mais de $62 \%$ dos brasileiros têm interesse por assuntos de C\&T. Entre os jovens de 15 a 24 anos, o interesse pela temática é um pouco maior: 67\%. Esse valor é maior, por exemplo, do que o interesse por esportes e arte e cultura nessa faixa etária (CGEE, 2019; INCT, 2019).

Em relação aos cientistas, eles são vistos como pessoas inteligentes, cujo trabalho possibilita beneficios para cerca de $40 \%$ dos brasileiros entrevistados. Os demais participantes veem esses profissionais como pessoas com treinamento especial, que se interessam por assuntos distantes da realidade e estão ligadas a demandas econômicas e com estudos em áreas nem sempre desejáveis. Além disso, cientistas possuem alto nivel de confiança (CGEE, 2019).

Essa percepção positiva da atividade cientíica é compartilhada por outros países latinoamericanos, como o Chile (CONICYT, 2016), a Colômbia (OCYT, 2014), o Panamá (SENACYT, 2017) e o México (INEGI, 2011).

Nos Estados Unidos e na União Europeia, o percentual de interesse da população pela temática é maior: $85 \%$ e $79 \%$, respectivamente. Entre os norte-americanos, apenas as novidades da medicina apresentam um enfoque mais acentuado, já que 95\% da população se interessa pelo assunto. Para os europeus, há a compreensão de que a ciência propicia uma vida mais saudável, confortável e fácil, sendo eles otimistas em relação à C\&T, acreditando no seu potencial de trazer beneficios concretos (EUROPEAN COMISSION, 2010; NSF, 2016).

Tal percepção positiva pode estar relacionada, em alguma medida, à abordagem midiática sobre a atividade científica, que tende a destacar as novidades da ciência e seus aspectos positivos, em diferentes paises e tipos de programação (SIQUEIRA, 1999; BARCA, 2004; LÓPEZ, 2012; NISBET; DUDO, 2013; ARBOLEDA CASTRILLÓN et al., 2015), uma vez que diversos estudos já apontaram que a TV pode ajudar a construir a imagem dos telespectadores sobre o conceito de ciência e de cientista (STEINKE et al., 2007: SCHÄFER, 2016).

No Reino Unido, Whitelegg e colaboradores (2008) verificaram uma relação estreita entre televisão e representação de cientistas em crianças e adolescentes. Dados similares foram registrados por Ruiz-Mallén e Escalas (2012) na Espanha e Soares e Scalfi (2014) no Brasil.

Em nosso país, é possivel que haja uma relação mais próxima entre a percepção pública da ciência e a programação televisiva, pois a TV - mesmo com a emergência das novas tecnologias - ainda é o principal acesso às informações cientificas para a população (CGEE, 2015).

Na Europa e nos Estados Unidos (EUROPEAN COMISSION, 2010; NSF, 2016), a internet vem se consolidando como uma fonte de informação relevante, contudo, no Brasil, ainda não se equiparou à importância da TV no cotidiano da população. Vale lembrar ainda que a televisão tem um papel determinante na sociabilidade, na constituição da agenda e nas pautas dos latinoamericanos como um todo - e em especial dos brasileiros - pois desempenha funções de fonte de informação, entretenimento, corporifica a integração nacional e tece as práticas culturais no país (REIMÃO, 2000; JACKS; MENEZES; PIEDRAS, 2008: MARTIN-BARBERO, 2009).

Nesse contexto, o público adolescente tornase um grupo de estudo relevante tanto em razão de sua proximidade com o meio de comunicação televisivo como por seu interesse em temáticas científicas, já que esse público é um dos que mais assistem TV: 76\% dos jovens de 16 e 17 anos assistem à televisão todos os dias e $41 \%$ deles, por mais de três horas diárias (MIDIA DADOS BRASIL, 2017; BRASIL, 2016).

Mesmo assim, são poucos os estudos voltados para análise da intersecção entre televisão, adolescentes e ciência no Brasil. Cazelli (2005), por exemplo, em seu estudo voltado para a relação entre jovens e museus de ciência, apurou que mais 90\% dos estudantes participantes de seu estudo assistiam à programas de TV sobre conteúdos de ciência - um percentual maior em relação aos demais meios de comunicação. Além disso, tais temáticas tornavam-se assuntos de conversações 
entre pais e filhos com frequência, segundo a autora, indicando um aprofundamento da discussão.

Soares e Scalfi (2014), por sua vez, observaram que jovens do ensino médio do estado do Ceará possuem percepções estereotipadas sobre o cientista e o seu trabalho, em especial em relação à sua vestimenta, seu tipo físico (homem) e seu local de trabalho (laboratório). As autoras entendem que a mídia, de uma forma geral, e a televisão, em particular, podem ter contribuido para a construção dessas representações no imaginário dos adolescentes.

Já Gomide (2016) verificou que estudantes do ensino médio, de escolas públicas e particulares da cidade de Belo Horizonte, percebem que a representação televisiva da ciência e do cientista é marcada por estereótipos e, não necessariamente, reflete a realidade. Por outro lado, a autora considera que existe uma postura conformista dos jovens frente a essas representações, uma vez que eles pouco questionam a origem dessas imagens.

Considerando, então, que os levantamentos recentes sobre os estudos de recepção brasileiros (SCHMITZ, 2014; JACKS, 2014) indicam um crescimento nas análises com esse público² sob as mais diversas perspectivas, propomos, neste artigo, uma pesquisa sobre a recepção de adolescentes a anúncios televisivos com conteúdos científicos da área da saúde.

Nosso objetivo é refletir sobre a forma com que esses jovens interagem com os conteúdos científicos presentes em anúncios publicitários veiculados pela TV aberta brasileira. A intenção é contribuir tanto para os estudos sobre a percepção pública da ciência quanto para as pesquisas de recepção com materiais publicitários, tendo como pano de fundo o principal meio de comunicação do País, a televisão.

\section{Ciência e publicidades televisivas}

Em sua pesquisa sobre a TV brasileira, Aronchi (2004) identificou as cinco principais categorias televisivas da nossa programação diária: entretenimento, informação, educação, publicidades e outras (que não se enquadram nas demais categorias). Segundo o autor, essas categorias contemplam as funções clássicas da televisão (de instruir, entreter, informar e ainda conferir espaço na grade aos anunciantes), materializando-se em diversos gêneros e formatos.

Embora o autor reconheça que a categoria publicidade possui cinco gêneros televisivos próprios, neste artigo, optamos por identificar as peças dessa categoria como "publicidades" de uma forma indiferenciada, buscando manter a unidade da classificação de Aronchi (2004), sem confundir ou criar disparidades entre conceitos e definições característicos da área de Publicidade e Propaganda. Logo, quando mencionamos "publicidades", estamos nos referindo a todas as peças identificadas na categoria televisiva "publicidade".

Em nosso levantamento bibliográfico sobre estudos televisivos relacionados a conteúdos científicos, observamos que os estudos voltados para a análise em publicidades são mais recentes, principalmente se compararmos com as pesquisas de jornalismo científico (BARCA, 2004; ALBERGUINI, 2007; RAMALHO; POLINO; MASSARANI, 2012; REZNIK et al., 2014).

Segundo Ippolito e Mathios (1990), o discurso publicitário se baseia em descobertas científicas com frequência. Contudo, os consumidores possuem dificuldades para conferir a veracidade de tais informações, uma vez que essas não estão acessiveis. Assim, as publicidades recorrem à ciência para atribuir autoridade e legitimidade, mas não possibilitam a checagem dos dados ou contestação de resultados, o que leva os consumidores a escolherem apenas em confiar ou não no discurso científico e publicitário para fazer suas escolhas e efetuar a compra.

Ribeiro (2016) afirma que o discurso do consumo, presente nas publicidades, ancorase na legitimidade das descobertas científicas das mais diferentes formas, seja no destaque às substâncias contidas nas fórmulas dos cosméticos que são capazes de reverter o envelhecimento natural do corpo, seja na ênfase de novas

\footnotetext{
2 No estudo de Schmitz (2014), a palavra "juventude" foi usada como sinônimo de "adolescentes" em várias pesquisas, porém, alguns casos incluiram outros públicos nessa nomenclatura.
} 
formas de se fazer cálculos para aumentar o rendimento bancário, ou seja nas tecnologias das telecomunicações que encurtam distâncias.

Já no estudo de Torres (2012) sobre as publicidades televisivas colombianas, o conhecimento científico foi utilizado como um recurso retórico. A maioria das peças tratava de produtos de cuidado com a saúde ou com o corpo e, nesses casos, o discurso científico evidenciava como o produto satisfazia as necessidades do consumidor. Assim, os objetos de consumo ofertados eram recriados como objetos científicos por meio do uso de diferentes recursos visuais, textuais e sonoros. Para o autor, a ciência adaptouse à narrativa publicitária, afastando-a dos seus objetivos de produção do conhecimento em si, e tornando-se uma motivadora de compra.

Rabello (2010), por sua vez, verificou que a ciência foi representada como viabilizadora da saúde e do bem-estar em publicidades televisivas de medicamentos. Apesar disso, a autora observou que a percepção do público sobre essas publicidades não se restringe às informações contidas nas peças, já que os consumidores entendem essas produções de uma forma ampla, associando-as uma rede de conceitos abstratos até a efetivação da compra.

Nesse sentido, visamos trazer mais dados e reflexões sobre essa percepção do público em relação aos conteúdos científicos presentes em publicidades televisivas brasileiras, uma vez que a pesquisa empírica de audiências na América Latina tem o potencial de contribuir para o conhecimento dos processos de consumo, negociação e apropriação de conteúdos televisivos, segundo Frankenberg, Lozano e Jacks (2009).

\section{Metodologia}

Visando identificar características atribuídas à ciência e aos cientistas por adolescentes, a partir de anúncios publicitários televisivos geradores de discussão, realizamos entrevistas semiestruturadas com adolescentes ${ }^{3}$, estudantes do segundo ano do ensino médio de escolas públicas e privadas da cidade do Rio de Janeiro. A proposta era englobar diferentes perfis socioeconômicos entre os participantes. Essa faixa etária foi selecionada por se tratar de um grupo que está em processo de escolha da profissão, além de ser um público próximo ao conteúdo midiático e/ou televisivo. Além disso, ao optarmos por jovens de uma mesma série escolar, mantivemos participantes com idades aproximadas, entre 16 e 19 anos.

Participaram da pesquisa 22 jovens, sendo 10 do gênero feminino e 12 do gênero masculino; 11 estudantes de escolas públicas e 11, de escolas particulares. As entrevistas foram realizadas entre setembro e outubro de 2014, nas próprias instituições de ensino.

Inicialmente, pedimos aos jovens que assistissem a cinco anúncios publicitários veiculados pelas emissoras de TV aberta brasileira de maior audiência em 2013 - TV Globo e TV Record (MÍDIA DADOS BRASIL, 2017) - em um notebook disponibilizado pela equipe de pesquisa. As peças eram dos seguintes produtos/marcas: Asepxia gel (medicamento para espinhas), Centrum (multivitamínico), Cicatricure (creme facial), Tio Nacho (shampoo) e Goicoechea (hidratante). A seguir, apresentamos as transcrições dos anúncios:

[Voz masculina] Asepxia desenvolveu um novo
medicamento, Asepxia Gel 10\%. O ativo de
Asepxia Gel 10\% elimina a bactéria P. acnes, que
está entre os principais causadores da acne.
Enquanto age, os grânulos antibacterianos de
peróxido de benzoila penetram profundamen-
te na pele para combater e eliminar a acne.
Resultados comprovados já no segundo dia
de tratamento. Nada melhor que um medi-
camento (ASEPXIA, TV RECORD, 19 ago. 2013).
[Personagem homem] Anos atrás meu médico
sugeriu que eu tomasse Centrum Select todos
os dias. Ele é formulado para pessoas com
mais de cinquenta anos, tem doses extras de
antioxidantes e ajuda a manter a energia e a
disposição. Ai eu li um estudo que comprovou:

Há divergências no conceito de adolescência de acordo com a instituição ou organização social. Enquanto a Organização Mundial da Saúde (OMS) estabelece como adolescentes aqueles jovens entre 10 e 19 anos de idade, o Estatuto da Criança e do Adolescente (ECA) delimita que o adolescente é uma pessoa entre 12 e 18 anos de idade (BRASIL, 2005). Considerando a limitação nacional do artigo, optamos pelo enquadramento do ECA. 
o uso contínuo de multivitamínicos traz sim benefícios a longo prazo para a minha saúde. E a marca utilizada no estudo foi Centrum, a mesma que eu tomo. [Narrador] Centrum Select, o mais vendido no mundo para pessoas acima de cinquenta anos (CENTRUM SELECT, TV GLOBO, 16 set. 2013).

[Voz masculina] A idade te marcou com rugas e flacidez? Cicatricure Creme Anti-idade revoluciona com seu ativo Regenext IV Complex, o componente rejuvenecedor de idade. Cicatricure Creme Anti-idade, o único creme com Regenext $I V$, que atua em dois niveis: hidrata e elimina as rugas. Hidrata profundamente estimulando o colágeno e a elastina, evitando a flacidez e elimina as rugas e linhas de expressão. Linha Cicatricure Creme Anti-idade, o acidente científico que pode mudar a idade da nossa pele (CICATRICURE, TV RECORD, 19 ago. 2013).

[Pesquisador R\&D] O nivel de exigência a que suas pernas são submetidas é maior que de qualquer outra parte do corpo. [Mulher 1] Eu subo e desço seis andares pelo menos quatro vezes ao dia. [Mulher 2] Em um dia eu posso caminhar até oito quilômetros. [Mulher 3] Eu fico em pé por doze horas contínuas. IPesquisador R\&D] Quando o nivel de exigência é assim alto, para estes casos existe Goicochea. Aplicar por 40 segundos é suficiente para relaxar as pernas, refrescá-las e melhorar sua aparência, inclusive em zonas com araninhas. [Narradora] Goicochea, meu especialista em pernas (GOICOECHEA, TV RECORD, 13 nov. 2013).

[Voz masculina] 1857. Dom Inácio Corcuera cria um xampu com a extraordinária capacidade de penetrar no folículo capilar, Xampu Tio Nacho. Esse fato se tornou um dos mais premiados do século Vinte. Dois mil e seis. Estados Unidos descobrem a fórmula mais eficaz para retardar o envelhecimento capilar a base de geleia real. Agora ambas tecnologias se juntam para criar um xampu extremamente efetivo que atrasa o aparecimento de cabelos brancos e evita a queda por seus ingredientes naturais. Apresentamos no Brasil a reformulação do novo xampu anti-idade Tio Nacho. Detenha os cabelos brancos, detenha a queda. Tio Nacho, o rei da geleia real (TIO NACHO, TV RECORD, 18 jun. 2013).

Os anúncios foram selecionados em uma fase anterior do projeto de pesquisa, cuja etapa inicial mapeou a presença de temas de ciência e tecnologia na programação diária das emissoras de maior audiência do País: TV Globo e TV Record. Em comum, as peças apresentavam menções ao processo científico de desenvolvimento do produto, citavam termos científicos, utilizavam ilustrações e animações para suas explicações ou ainda mostravam personagens da área científica - pesquisadores - em suas narrativas, como no caso dos anúncios dos produtos Goicoechea e a do Asepxia gel, cujos personagens vestiam jalecos e estavam em laboratórios.

Além disso, a escolha por anúncios desse setor econômico se justifica por duas razões. Primeiro, por ser um setor importante no panorama da publicidade brasileira, já que quatro entre os dez maiores anunciantes em espaços publicitários no Brasil, nos últimos anos, são da área farmacêutica. Esse setor já investe mais de 10 milhões de reais por ano em suas campanhas, veiculadas em todas as midias - embora a TV aberta ainda seja o meio de comunicação mais escolhido pelos anunciantes. Juntamente com os anunciantes da área de higiene pessoal e beleza, o setor farmacêutico produz peças publicitárias voltadas para medicamentos e produtos cosméticos para diversos fins e ambos têm marcado presença no ranking dos maiores anunciantes do País (KANTAR IBOPE MÍDIA, 2017, 2018)

A segunda justificativa se dá em razão de outros estudos já terem apontado que as produções publicitárias desse setor tendem a tratar de assuntos científicos com frequência (RABELLO, 2010; TORRES, 2012; RIBEIRO, 2016). Lucas e Hoff (2007), por exemplo, observam que a veiculação de informações "aparentemente" científicas em narrativas publicitárias de produtos cosméticos e medicamentos ultrapassa os padrões de rigor da ciência. Tal característica torna-se evidente na opção por enfatizar ou as substâncias responsáveis pelos efeitos prometidos ou apenas as promessas desses efeitos, em detrimento da abordagem do processo científico como um todo. As autoras ressaltam que esse tipo de argumentação está cada vez mais comum, gerando uma "cientifização" das publicidades.

Depois que os adolescentes assistiram as peças, iniciamos as entrevistas propriamente ditas, a partir de um roteiro previamente estruturado, que apresentava os seguintes eixos temáticos: impressão geral sobre o anúncio, percepção do processo cientíico e identificação/representação do cientista.

Optamos pela metodologia de entrevistas, pois esta possibilita maior flexibilidade na obtenção de informações dos participantes e reduz os riscos 
de má compreensão das perguntas, segundo Selltiz e colaboradores (1974). Tal metodologia é adequada a vários públicos e possibilita ao entrevistador a checagem dos dados, pontos de vista dos entrevistados e esclarecimento de contradições e controvérsias. Para Gaskell (2002), essa metodologia é uma forma de mapear e compreender o modo de vida dos respondentes e de criar esquemas interpretativos para esses comportamentos em contextos especificos. Ou seja, a entrevista qualitativa fornece "dados básicos para o desenvolvimento e a compreensão das relações entre os atores sociais e sua situação" (GASKELL, 2002, p. 64).

Dessa forma, não pretendemos fazer generalizações sobre a totalidade dos adolescentes cariocas ou brasileiros e sua relação com conteúdo cientifico e televisão. Ao contrário, buscamos refletir sobre tais relações de uma forma mais individualizada e aprofundada, visando identificar caracteristicas importantes nesse contexto midiático e discuti-las à luz dos estudos de percepção pública da ciência, divulgação científica e comunicação. Neste artigo, portanto, voltamo-nos para a análise de dois eixos principais de discussão: a ciência como argumento de venda e a identificação do personagem que recomenda o produto e seu papel na narrativa publicitária.

\section{A percepção sobre a ciência em publicidades televisivas brasileiras}

Todos os adolescentes conheciam pelo menos um dos anúncios publicitários apresentados. Entre os 22 entrevistados, nove já haviam comprado algum dos produtos anunciados e outros oito, após assistirem às peças, indicaram ter interesse em comprar um dos itens. Quatro jovens mostraram interesse pelos produtos Asepxia, principalmente em razão de possuírem acne, mas também por causa do anúncio em si. Um dos participantes explicou que compraria o produto porque a peça "é convincente. E você, querendo a solução do problema, você corre atrás do que pode ser a solução. Então, seria uma via para que a acne vá embora" (Informação verbal). ${ }^{4}$

Justificativa semelhante foi dada pelo adolescente que compraria o multivitaminico Centrum, em razão de sua prática de esporte e necessidade de "repor energia". Ou seja, a razão para a compra parte de uma necessidade: ou a (redução da) acne ou a (necessidade de) energia.

Por outro lado, os três jovens que comprariam o shampoo Tio Nacho destacaram que o anúncio foi determinante para eles terem o interesse em comprar o produto. Eles ressaltaram como diferencial da peça a história do produto, as imagens de laboratório (produção) e de jornais antigos, a linguagem "chamativa" e a "voz imponente".

Percebemos, então, que os entrevistados fazem a escolha da compra com base em suas necessidades e também nas narrativas da publicidade, como no caso da peça do produto Tio Nacho. Tais justificativas remetem à percepção de Baccega (2014) sobre a forma com que comunicação e o consumo se relacionam, que é, justamente, no âmbito da difusão dos produtos e serviços, quando estes são apresentados como necessidades dos individuos consumidores. Além disso, a autora destaca a importância da publicidade nos dias de hoje, também chamada de "era da publicidade", devido à transformação das coisas e sentimentos em mercadorias.

A autora lembra ainda que os bens (a consumir e consumidos) constituem uma das bases da construção das identidades dos sujeitos, consolidando suas duas faces inseparáveis: a material e a simbólica. Por isso, questões como a construção da verdade, dos estereótipos, do imaginário, das identidades, entre muitos outros aspectos sociais e culturais, constituem o foco de discussão dos estudos sobre o consumo.

Quando perguntados qual seria o "melhor anúncio", 14 participantes indicaram o shampoo incluindo os três que se interessaram em comprálo. Novamente, eles destacaram como ponto alto da narrativa a questão histórica, "porque ele explicou o passo a passo da evolução da

4 Estudante 01, gênero masculino, escola particular, Rio de Janeiro, 2014. 
tecnologia, do começo ao fim" (Informação verbal)5. Uma das adolescentes argumenta:

Eu gostei bastante da [peça do produto] Tio Nacho. Porque eu acho que, quando fala um pouco da história do produto, fica bem legal. A imagem também ficou bacana. Não ficou uma coisa forçada, de vários atores fazendo a mesma coisa, ficou falando sobre a história do produto. Ficou bem interessante [...]. Diz que o produto é bom. E a própria visualização das imagens, que são vários jornais sendo transpostos também, falando sobre as pesquisas, é bem bacana. Diferente de mostrar só pessoas usando (Informação verbal). ${ }^{6}$

A narrativa da peça do Tio Nacho, de fato, difere das demais por trazer uma voz narradora masculina bastante enfática, semelhante a aberturas de filmes cinematográficos. Contudo, para além da voz, os jovens pareceram conferir credibilidade às imagens de jornais contidas na peça, que narravam o desenvolvimento do produto.

Apesar desses dois fatores terem chamado a atenção dos adolescentes, eles ainda se mostraram céticos quanto ao produto - alguns mais do que outros. Uma das entrevistadas disse que o anúncio "é muito fantasioso. Até pela história que o 'cara' [sic] criou e que foi um shampoo revolucionário nos Estados Unidos. Eu acho que não foi nada disso" (Informação verbal). ${ }^{7}$

Nesse caso, apenas duas jovens afirmaram acreditar nos efeitos prometidos pelas peças publicitárias de uma forma geral, enquanto cinco declaram não acreditar em nada veiculado em tais peças. Uma participante justificou seu posicionamento dessa forma: "Não, não acredito não, porque na propaganda, os atores são muito forçados, é uma coisa muito só para poder te induzir a comprar o produto [...]. Dá a impressão de que é mentira" (Informação verbal). ${ }^{8}$

Porém, a maior parte dos participantes relativizou esses conteúdos televisivos. Alguns indicaram que seria necessário "testar para ver" os produtos; outros que os resultados não seriam "imediatos" como os anúncios prometem; ou ainda que "cada pessoa reage de uma forma". Recorrentemente, eles disseram que acreditam nas publicidades, "mas não em tudo".

Tal ponderação e resistência já foi observada em outras pesquisas, como a de Trindade e Moreira (2010), por exemplo. Os autores desenvolveram um estudo com familias de diferentes classes sociais, verificando que havia uma resistência quanto à publicidade, de uma forma geral. Ou seja, as familias mostraram-se receosas e críticas quanto às peças, embora as consumissem e as considerassem nas escolhas de consumo diárias - assim como os participantes desta pesquisa.

Por sua vez, Toaldo e Malcher (2017) perceberam que jovens adultos (entre 18 e 24 anos) conseguem assistir aos anúncios, refletir, ponderar e avaliar as peças de diversas formas, de acordo com suas vivências e experiências - e ainda compreendem que tais anúncios visam incentivar o consumo.

É possivel ver, então, a competência textual e narrativa desses adolescentes em relação aos materiais televisivos, especialmente os publicitários. Como diz Martín-Barbero (2009, p. 304), um telespectador sabe quando o texto foi interrompido, possui capacidade de interpretá-lo e resumi-lo, ou seja, são individuos "falantes do idioma dos gêneros" que negociam os sentidos a partir dos conteúdos da televisão.

Nesse sentido, os entrevistados destacaram o papel da TV no processo de persuasão de a compra e venda de produtos. Afirmaram que a televisão "convence, porque coloca a foto de uma pessoa cheia de espinhas ou acnes e mostra como se fosse algo científico, que você passa e acaba la acne]. E a pessoa não fica com marca nenhuma" (Informação verbal)9.

Vale lembrar, portanto, que, na América Latina, a televisão "familiariza tudo, torna 'próximo' até o que houver de mais remoto", segundo MartinBarbero (2009, p. 297). Para o autor, a sensação de imediatez, de algo que acontece agora e em um lugar próximo é um dos grandes destaques

\footnotetext{
Estudante 02, gênero feminino, escola pública, Rio de Janeiro, 2014 Estudante 03. gênero feminino, escola particular, Rio de Janeiro, 2014

Estudante 04, gênero feminino, escola pública, Rio de Janeiro, 2014.

Estudante 05, gênero feminino, escola particular, Rio de Janeiro, 2014

Estudante 04, gênero feminino, escola pública, Rio de Janeiro, 2014.
} 
da TV. É essa imediatez que confere transparência e possibilita a familiaridade, a proximidade dos telespectadores com seus programas. No Brasil, mais especificamente, a TV ainda é um importante elemento do cotidiano, mesmo após a ascensão e consolidação das novas tecnologias (REIMÃO, 2000; MATTOS, 2010; BRASIL, 2016).

\section{Ciência como argumento de convencimento e venda}

De uma forma geral, os adolescentes percebem que o uso de argumentos científicos em publicidades televisivas é recorrente e reconhecem que tal recurso traz credibilidade aos produtos e às marcas. Contudo, apenas quatro jovens afirmaram que a menção ao "cientificamente provado" ou "testado clinicamente" - entre outros dizeres semelhantes - era um diferencial ou o determinante para a compra.

A maioria dos entrevistados entendia que as citações à ciência são um recurso de "marketing", "para impressionar", "chamar atenção" e, nem sempre, condizia com a realidade. Mais uma vez, tais percepções exemplificam a competência de leitura dos participantes da pesquisa, como no depoimento a seguir.

Porque podem falar que é cientificamente provado, mas não funciona como está mostrando no comercial. Pode ser que funcione um pouco, mas nem tanto como mostra. Eles podem usar como se fosse muito bom. Mas quando for usar realmente, não funciona tanto como aparece no comercial (Informação verbal). ${ }^{10}$

Outro ponto que eles ressaltaram como razão para essa desconfiança em relação às menções a conteúdos científicos foi a atuação das empresas na construção das narrativas publicitárias. Para os participantes, os consumidores "podem ser enganados pelo lucro das empresas" e podem acreditar em "propagandas enganosas" facilmente, porque não há como garantir que os resultados prometidos foram, de fato, "comprovados cientificamente".
Um dos jovens mencionou, inclusive, que uma das formas de garantir a veracidade dos conteúdos científicos seria por meio de um "reality show, mostrando cada etapa [do processo científico], mostrando o que eles fizeram" (Informação verbal).11

Além das competências narrativas apresentadas pelos adolescentes, tais reflexões indicam seu perfil bastante critico, uma vez que reconhecem os atores e as diversas questões envolvidas na produção da peça televisiva. Esse perfil crítico, porém, não é uma surpresa, uma vez que Laurindo e Leal (2008) já observaram que em crianças de até cinco anos de idade conseguem identificar características das publicidades televisivas.

Tal criticidade também se relaciona às práticas de recepção que, segundo Piedras e Jacks (2006), encontram-se mais vinculadas com as condições contextuais dos sujeitos do que com a reprodução do sentido hegemônico. Ou seja, os indivíduos - a exemplo dos entrevistados nesta pesquisa podem fazer diversas interpretações e distintos usos das mensagens televisivas, reconhecendo sua lógica e ponderando sobre a mesma.

Já a menção a termos científicos em peças publicitárias televisivas se deve, de acordo com os entrevistados, ao fato de que os telespectadores/ consumidores pouco conhecem esses termos - e esse desconhecimento confere credibilidade e confiança. Um dos adolescentes declarou que "não dá para entender o que ele falou, mas parece ser um nome difícil, parece que funciona mesmo. Tipo, porque é difícil e a gente não entende, eles entendem mais. E a gente acaba comprando pelo nome às vezes, por causa do que eles explicam assim, mais ou menos" (Informação verbal).12 Essa foi uma percepção comum entre 15 participantes, dentes os quais indicamos os exemplos a seguir.

O que eu acho é que essas propagandas falam de uma forma difícil para o povo não entender. Porque tem muitas linguagens que eles usam nessas propagandas, que muita gente não entende. [...] A forma que eles falam sobre a doença, que eles falam em inglês, bactérias. Muitas pessoas não têm esse conhecimento. 
Então, eles têm que trazer de uma forma que todos entendam (Informação verbal).13

Eu acho que pelo fato mesmo de a gente não conhecer os termos, mas pelo fato de eles estarem citando, dá um ar de estar passando mais a verdade, estar mostrando a fórmula química, está mostrando as vitaminas. Então, parece que é verdadeiro mesmo. Então, leva a você acreditar mesmo que é bom. (Informação verbal). ${ }^{14}$

Essa construção de um cenário científico, a partir do uso termos cientificos e das menções ao "cientificamente provado", pode ter contribuido para a representação da ciência como algo "misterioso, complexo e até impossivel de ser conhecido" - a exemplo da imagem que Rabello (2010, p. 96) identificou em publicidades de medicamentos.

Tal representação, a nosso ver, gera duas questões principais. Primeiro, como os entrevistados relataram, ao destacar termos "incompreensiveis" ou sem explicação, é possivel chamar a atenção dos telespectadores consumidores, mesmo que esses não consigam entender toda a mensagem presente na peça. Ou seja, a ciência torna-se um motivador de compra em si mesma - mesmo sem a explicação devida ou clareza nas informações.

Em segundo lugar, refletimos sobre o questionamento de Torres (2012) em relação ao papel da publicidade televisiva na popularização da ciência, uma vez que tais produções trabalham as temáticas científicas com bastante frequência - mesmo que o seu objetivo não seja fazer a divulgação cientíica. O autor destaca que o fato dessas programações visarem à venda dos produtos não torna, necessariamente, os seus conteúdos científicos menos confiáveis, pois estes não deixam de ser "ciência" ao serem apresentados nas publicidades.

Entendemos que este é um questionamento importante, principalmente no cenário latinoamericano - com suas dificuldades educacionais e com a "familiaridade" que a televisão cria nesse cenário (MARTIN-BARBERO, 2009). Podemos nos perguntar, então, até que ponto os telespectadores têm acesso à ciência por meio das publicidades e reconhecem a atividade científica pelos seus termos técnicos, que são tão frequentes em suas narrativas.

Ainda nesse eixo de discussão, lembramos que Schäfer (2016) entende que a confiança do público no conhecimento científico se deve, em alguma medida, às imagens veiculadas por esses meios. Em razão da distância entre o meio acadêmico e a sociedade, é possivel que as representações midiáticas tenham um impacto na forma com que o público vê, entende e confia na ciência - assim como outros temas, a exemplo de economia e política, segundo o autor.

Assim, é possivel que esta imagem "misteriosa", "difícil" e até "incompreensiva" da ciência em publicidades televisivas possa ter um papel na construção da representação da ciência como um todo $E$ essa representação também apresenta duas caraterísticas contraditórias: ao mesmo tempo que é incompreensivel, também é indicação de credibilidade.

\section{O personagem que recomenda o produto: médico ou cientista?}

No anúncio da marca Goicoechea, o apresentador e narrador da peça estava identificado como pesquisador R\&D (Research \& Development, sigla em inglês para Pesquisa \& Desenvolvimento). Porém, a maioria dos adolescentes não conseguiu gravar a função e/ou a titulação do pesquisador, tendo dúvidas quanto à sua profissão

Uma possivel razão para essa dúvida, pode ser o uso indiscriminado do rótulo de "especialistas" pela programação televisiva. Wurff, Verhoeven e Gadellaa (2013) destacam que muitos dos cientistas identificados em sua pesquisa com telejornais haviam sido apresentados dessa forma, ao passo que Torres (2012) também observa uma utilização indiferenciada entre especialistas e cientistas nas publicidades e nos meios de comunicação de uma forma geral.

Entre os participantes da pesquisa, 16 identificaram o personagem como médico. Para 
eles, o médico é uma das principais autoridades na área da saúde e, já que o produto se volta para tal área, ele seria o profissional mais adequado para recomendar o produto, como vemos nos depoimentos a seguir.

Ter uma imagem de um médico passa a ter mais crédito com a população. Porque, por exemplo, se ele estudou isso e está certo disso, ele vai te recomendar e você vai seguir os procedimentos. Como entre outras doenças, no caso, que a gente vai no médico, ele te recomenda, passa e cura (Informação verbal). ${ }^{15}$

Ele fala sobre como o produto funciona. Eu o vejo como um médico, eu o vi como um médico. E acredito que a maioria das pessoas deva achar, até pela roupa dele e da maneira que ele fala [...]. Achei que ele falou com muita propriedade. E isso é muito importante. Assim, ele falou com uma voz forte, no sentido de que realmente ele está falando a verdade sobre o produto (Informação verbal). ${ }^{16}$

Apesar do destaque para o profissional da medicina, o personagem também foi identificado como cientista por sete entrevistados - mesmo que alguns tenham afirmado que ele poderia ser tanto um cientista como um médico. Nesse caso, os jovens inferiram que o personagem fazia parte da equipe de pesquisadores que desenvolveu o produto e, portanto, também seria uma pessoa autorizada a falar e recomendar o produto.

Ele é um dos cientistas que ajuda a criar o produto, ele que manda fazer e tal. E ele está ali reforçando a ideia do produto dele, querendo mostrar que ele é. Ele vai com um uniforme. parecendo um cientista, para mostrar que é realmente verdade, para chamar mais a atenção. Que é um cientista (Informação verbal). ${ }^{17}$

Outros quatro adolescentes indicaram que havia a possibilidade de ser um ator fazendo o papel ou de um cientista ou de um médico. Mesmo assim, eles compreenderam que, qualquer que seja a real profissão do personagem, o seu papel é conferir credibilidade e autoridade para o produto e à marca. Esse reconhecimento de confiança em cientistas e médicos condiz com a enquete brasileira de percepção de ciência
(CGEE, 2019), na qual temos o cientista como o profissional com maior nível de credibilidade, seguido por jornalistas e médicos.

A existência do discurso de autoridade proferido por especialistas em peças publicitárias da área de saúde já foi observada por outros autores (TORRES, 2012; SANTANA et al. 2013). Segundo Santana e colaboradores, esse é um recurso publicitário estratégico para chamar a atenção do público, uma vez que destaca pessoas que dominam o assunto da saúde e utilizam valores científicos para argumentar com a audiência, conferindo mais segurança ao consumidor.

Um destaque desta pesquisa é que nove participantes discorreram sobre as diferenças entre cientistas e especialistas - no caso da peça da marca Goicoechea, um médico. De acordo com os jovens, a atividade de cientista está mais relacionada à teoria, à inovação, ao trabalho em laboratório, à pesquisa na composição do produto e ao conhecimento de suas funcionalidades. Ou seja, está sempre "estudando fórmulas para descobrir algo novo". Já o médico trabalha em um processo posterior ao da pesquisa científica. Trabalha em hospitais e possui atividades mais práticas, ligadas ao cuidado dos seus pacientes, identificação de sintomas, indicação de tratamentos e recomendação de medicamentos.

Um pesquisador não tem a mesma coisa que
um médico. Igual, um enfermeiro não é igual
a um médico. Pesquisador é uma pessoa que
está pesquisando. Mas o médico é aquela
pessoa na ação. A diferença é muito grande,
porque um pesquisador está pesquisando, está
sabendo o que ele está estudando. Mas o mé-
dico é mais na prático. Então, ele sabe se é sim
ou não. Mas um pesquisador. Eu acho que tem
muita diferença [...]. Eu acho que pesquisador
é só teoria, não é prática (Informação verbal). ${ }^{18}$

Outra diferença entre os dois profissionais seria a amplitude de seu conhecimento. Para uma entrevistada, o "especialista está voltado para uma área só, para um produto só, é especialista em um único produto. Então, ele vai falar e vai

\footnotetext{
Estudante 12, gênero masculino, escola pública, Rio de Janeiro, 2014.

Estudante 03, gênero feminino, escola particular, Rio de Janeiro, 2014

Estudante 06, gênero masculino, escola pública, Rio de Janeiro, 2014

18 Estudante 13, gênero feminino, escola pública, Rio de Janeiro, 2014.
} 
saber falar de um único produto, de uma única coisa. Já o cientista é praticamente obrigado a saber e falar sobre tudo" (Informação verbal). ${ }^{19}$

Essa concepção do cientista como aquele individuo que atua, principalmente, em laboratórios, lida com fórmulas e teorias e está sempre em busca descobertas se relaciona ao perfil tradicional - marcado por estereótipos - desse profissional, que já foi identificado em diversos estudos, de diferentes paises e em faixas etárias variadas (ROSA et al., 2005; WHITELEGG et al., 2008; LAUBACH; CROFFORD; MAREK, 2012).

Por outro lado, os entrevistados veem os especialistas, e os médicos mais especificamente, como profissionais que trabalham na prática do dia a dia e, portanto, não desenvolvem pesquisa ou "descobrem" novidades para a sua área. Embora não seja uma interpretação inteiramente errônea, essa separação entre as funções de cada reduz a complexidade de ambos os profissionais.

Nesse caso, essa percepção pode estar relacionada ao que Schäfer (2016) entende como a distância entre o meio acadêmico e a sociedade, uma vez que as representações midiáticas - que comumente focam nos aspectos estereotipados desses profissionais (ROSA et al., 2005; SIQUEIRA, 2006; RAMALHO; POLINO; MASSARANI, 2012; PEDREIRA, 2014) - reverberam na maneira com que o público entende esses conceitos e atores sociais.

\section{Considerações finais}

Neste artigo, buscamos refletir sobre a forma com que adolescentes brasileiros interagem com os conteúdos científicos presentes em publicidades televisivas, veiculadas pelas emissoras de maior audiência do país. A partir de uma metodologia qualitativa, percebemos a semelhança com os indicadores da última enquete de percepção pública da ciência (CGEE, 2015), especialmente na confiança em cientistas e médicos como fontes de informação e na concepção um tanto estereotipada - apesar de positiva - desses pesquisadores.

Percebemos, então, que é possivel que os anúncios publicitários - televisivos ou não - possam contribuir para a construção da representação da ciência e dos cientistas por parte do público, como Torres (2012) já havia sugerido em estudo anterior. Mesmo que a proposta dessas peças não seja fazer divulgação científica ou construir tais percepções, a publicidade em si é um processo comunicativo constitutivo de práticas culturais e, como tal, produz sentido em suas práticas de produção e recepção (PIEDRAS; JACKS, 2006), considerando a competência narrativa e textual dos receptores (MARTIN-BARBERO, 2009).

Além disso, diversos autores já registram o perfil crítico de diferentes grupos sociais frente às publicidades (TRINDADE; MOREIRA, 2010; RABELLO, 2010; TOALDO; MALCHER, 2017; LAURINDO; LEAL, 2008). Tal criticidade, reflexão e relativização de conteúdos também poderiam contribuir nas percepções sobre a atividade científica.

Talvez, a ideia de uma ciência "difícil", "misteriosa" e afastada da realidade social e do cientista como um profissional que se volta apenas para a teoria, se relacione com a apresentação de termos científicos não explicados, de uma linguagem rebuscada e não acessivel das publicidades, como os entrevistados relataram. Por outro lado, apesar da dificuldade de entender as mensagens, a ciência continua a ter importância na narrativa e credibilidade entre os jovens. É nesse sentido que os conteúdos científicos se tornam, também, motivadores de compra (ROSA, 2005; LUCAS; HOFF, 2007; MELLO, 2009; TORRES, 2012).

Os adolescentes participantes desta pesquisa mostraram esse perfil reflexivo e crítico em vários momentos, ponderando sobre a narrativa publicitária, os atores envolvidos e seus discursos. Eé esse perfil crítico e reflexivo dos adolescentes que caracteriza a sua competência narrativa para entender a diferenciação dos gêneros televisivos e evidencia sua fluência no idioma da televisão, mostrando que são nativos de uma dinâmica cultural latino-americana, como afirma Martin-Barbero (2009). 


\section{Referências}

ALBERGUINI, A. A ciência nos telejornais brasileiros (o papel educativo e a compreensão pública das matérias de C\&T). 2007. 300f. Tese (Doutorado em Comunicação Social) - Universidade Metodista de São Paulo, São Paulo, 2007. https://doi.org/10.1590/1983-211720175170110.

ARBOLEDA CASTRILLÓN, T. et al. Ciencia y tecnología en los telediarios colombianos: sobre lo que se cubre y no se cubre. Ensaio Pesquisa em Educação em Ciências, Belo Horizonte, v. 17, n. 1, p. 208-229, 2015.

ARONCHI, J. Gêneros e formatos na televisão brasileira. São Paulo: Summus, 2004.

BACCEGA, M. Comunicação e Consumo. In: CITELLI, A.; BERGER, C.; BACCEGGA, M.; LOPES, M.; FRANÇA, V. (org.) Dicionário de comunicação: escolas, teorias e autores. São Paulo: Contexto, 2014, p. 53-65.

BARCA, L. Iguarias à Hora do Jantar: a Presença de Ciência e Tecnologia nos Telejornais Diários. 2004. 266 f. Tese (Doutorado em Educação, Gestão e Difusão em Ciências) - Universidade Federal do Rio de Janeiro, Rio de Janeiro, 2004.

BRASIL. Estatuto da Criança e do Adolescente. Lei Federal $n^{\circ} 8069$, de 13 de julho de 1990. 6. ed. Brasilia, DF: Senado Federal, Subsecretaria de Edições Técnicas, 2005.

BRASIL. Presidência da República. Secretaria de Comunicação Social. Pesquisa brasileira de mídia 2016 hábitos de consumo de mídia pela população brasileira. Brasilia, DF: Secom, 2016.

CAZELLI, S. Ciência, cultura, museus, jovens e escolas quais as relações. 2005. 260 f. Tese (Doutorado em Educação) - Pontifícia Universidade Católica do Rio de Janeiro, Rio de Janeiro, 2005.

CENTRO DE GESTÃO E ESTUDOS ESTRATÉGICOS (CGEE). Percepção Pública de C\&T no Brasil: resumo executivo. Brasilia, DF: Centro de Gestão e Estudos Estratégicos, 2019.

COMISIÓN NACIONAL DE INVESTIGACIÓN CIENTÍFICA Y TECNOLÓGICA (CONICYT). Encuesta nacional de percepción social de la ciencia y la tecnología en Chile 2016. Santiago: Departamento de Estudios y Gestión Estratégica, 2016.

EUROPEAN COMMISSION. Science and Technology, [s. l.], 2010. Disponivel em: http://ec.europa.eu/public_opinion/archives/eb_special_359_340_en.htm. Acesso em 15 abr. 2019.

FRANKENBERG, L.; LOZANO, J.; JACKS, N. Audiências televisivas latino-americanas: 15 anos de pesquisa empírica. Matrizes, São Paulo, ano 3, n. 1, p. 167-196, ago./dez., 2009. https://doi.org/10.11606/issn.1982-8160.v3i1p167-196.

GASKELL, G. Entrevistas individuais e grupais. In: BAUER, M.; GASKELL, G. Pesquisa qualitativa com texto, imagem e som: um manual prático. Petrópolis: Vozes, 2002. p. 64-89.
GOMIDE, A. Gênero, ciências e midia: representações de mulheres cientistas entre estudantes do $2^{\circ}$ ano do ensino médio em Belo Horizonte. 2016. 166f. Dissertação (Mestrado em Sociologia) - Universidade Federal de Minas Gerais, Belo Horizonte, 2016.

INSTITUTO NACIONAL DE ESTADISTIICA Y GEOGRAFÍA EN MÉXICO (INEGI). Encuesta sobre la Percepción Pública de la Ciencia y la Tecnología en México 2011 (ENPECYT). [S. l.]: INEGl, 2013.

INSTITUTO NACIONAL DE CIÊNCIA E TECNOLOGIA EM COMUNICAÇÃO PÚBLICA DA CIÊNCIA E TECNOLOGIA (INCT-CPCT). O que os jovens brasileiros pensam da ciência e da tecnologia? Resumo Executivo, [s. l.], 2019. Disponivel em: http://ww/w.coc.fiocruz.br/images/PDF/ Resumo\%20executivo\%20survey\%20jovens_FINAL.pdf. Acesso em: 1 ago. 2019

IPPOLITO, P.; MATHIOS, A. The regulation of science-based claims in advertising. Journal of Consumer Policy, Paises Baixos, v. 13, n. 4, p. 413-445, 1990.

JACKS, N. (coord.); MENEZES, D.; PIEDRAS, E. Meios e audiências: a emergência dos estudos de recepção no Brasil. Porto Alegre: Sulina, 2008.

JACKS, N. Recepção televisiva, (ainda) a mais estudada. In: JACKS, Nilda (org.). Meios e audiências II: a consolidação dos estudos de recepção no Brasil. Porto Alegre: Sulina, 2014. p. 31-72.

KANTAR IBOPE MÍDIA. Mais de 60 mil anunciantes investiriam em publicidade no Brasil em 2017, [s. l.], 2018. Disponivel em: https://Ww/w.kantaribopemedia. $\mathrm{com} / \mathrm{mais}$-de-6o-mil-anunciantes-investiriam-em-publicidade-no-brasil-em-2017/. Acesso em: 15 abr. 2019.

KANTAR IBOPE MIDIA. Retrospectiva e perspectiva 2017, [s. l.], 2017. Disponivel em: https://www.kantaribopemedia.com/retrospectiva-perspectivas-2017-download/. Acesso em: 15 abr. 2019.

LAUBACH, T:; CROFFORD, G.; MAREK, E. Exploring Native American Students' Perceptions of Scientists. International Journal of Science Education, Taiwan, n. 11, v. 34, p. 17691794, 2012. https://doi.org/10.1080/09500693.2012.689434.

LAURINDO, R.; LEAL, A. A recepção da publicidade na TV entre crianças de cinco anos. Comunicação Midia e Consumo, v. 5, n. 13, p. 139-157, 2008.

LÓPEZ, V. Encuentro con la comunicación pública de la ciencia en la TV argentina. La trama de la comunicación, v. 16, n. 2, p. 269-283, 2012.

LUCAS, L.; HOFF, T. Da cronobiologia aos neurocosméticos: o advento do corpo-mídia no discurso publicitário da beleza. In: ENCONTRO ANUAL DA COMPÓS, 15., 2006, Bauru. Anais [...]. Porto Alegre: Sulina, 2007. p. 93-112.

MARTÍN-BARBERO, J. Dos meios às mediações: comunicação, cultura e hegemonia. 6. ed. Rio de Janeiro: Editora UFRJ, 2009.

MATTOS, S. História da televisão brasileira: uma visão econômica, social e política. 5 ed. Petróplis: Editora Vozes, 2010 
MELLO, L. Campanhas publicitárias 'vendendo saúde' discurso 'científico' e consumo construindo modelos de visa saudável. 2009. 186 f. Dissertação (Mestrado em Educação) - Universidade Federal do Rio Grande do Sul, Porto Alegre, 2009.

MÍDIA DADOS BRASIL. Televisão. 2017. Disponivel em: https://dados.media/\#!/dashboards/TELEVISION. Acesso em: 22 set. 2017.

NATIONAL SCIENCE FOUNDATION (NSF). Science \& Engineering indicators 2016. [S. l.]: National Science Foundation, 2016. Disponivel em: https://wwww.nsf.gov/ statistics/2016/nsb20161/\#/. Acesso em: 15 abr. 2019.

NISBET, M.; DUDO, A. Entertainment Media Portrayals and Their Effects on the Public Understanding of Science. In: NELSON, D. et al. (ed.). Hollywood Chemistry: When Science Met Entertainment. [S. L.]: American Chemical Society, 2013. p. 241-249. https://doi.org/10.1021/ bk-2013-1139.cho20.

OBSERVATORIO COLOMBIANO DE CIENCIA Y TECNOLGIA (OCYT). Percepciones de las ciencias y las tecnologias en Colombia: resultados de la III Encuesta Nacional de Percepción Pública de la Ciencia y la Tecnología. Bogotá: Observatorio Colombiano de Ciencia y Tecnologia, 2014.

PEDREIRA, A. Gênero, ciência e TV: representações dos cientistas no Jornal Nacional e no Fantástico. 2014. 158 f. Dissertação (Mestrado em Ensino em Biociências e Saúde) - Fundação Oswaldo Cruz, Rio de Janeiro, 2014.

PIEDRAS, E.; JACKS, N. A contribuição dos estudos culturais para a abordagem da publicidade: processos de comunicação persuasiva e as noções "articulação" e "fluxo". E-Compós, Brasilia, DF, v. 6, 2006. https://doi. org/10.30962/ec.v6io.74

RABELLO, E. Representações sociais mobilizadas pela propaganda televisiva de medicamentos: intersecções entre ciência, saúde e práticas de consumo. 2010. 108 f. Dissertação (Mestrado em Saúde Coletiva) - Universidade do Estado do Rio de Janeiro. Rio de Janeiro, 2010.

RAMALHO, M.; POLINO, C.; MASSARANI, L. Do laboratório para o horário nobre: a cobertura de ciência no principal telejornal brasileiro. Journal of Science Communication, [s. l.], v. 11, p. 1-10, 2012. https://doi. org/10.22323/2.11020202.

REIMÃO, S. A televisão no Brasil - ontem e hoje. In: REIMAO, S. Televisão na América Latina: 7 estudos. São Bernardo do Campo: Universidade Metodista de São Paulo, 2000. p. 7-10.

REZNIK, G. et al. Ciência na televisão pública: uma análise do telejornal Repórter Brasil. Alexandria, Florianópolis, v. 7, p. 157-178, 2014

RIBEIRO, L. Ciência como critério de verdade no imaginário das representações midiáticas. INTERIN, Paraná, v. 8, n. 2, 2016.

ROSA, A. Publicidade científica: um estudo do modo de organização do discurso argumentativo em revistas femininas. 2005. 150f. Dissertação (Mestrado em Letras e Lingüística) - Universidade Federal de Pernambuco, Recife, 2005
ROSA, M.; LUDWIG, B.; WIRTH, I. Os cientistas nos desenhos animados e os olhares das crianças. In: ENCONTRO NACIONAL DE PESQUISA EM EDUCAÇÃO EM CIÊNCIAS, 5., 2005, Bauru. Anais [...]. Bauru: [s. n.], 2005.

RUIZ-MALLÉN, I.; ESCALAS, M. Scientists seen by children: a case study in Catalonia, Spain. Science Communication, [s. l.], v. 34, n. 4, p. 520-545, 2012 https://doi.org/10.1177/1075547011429199.

SANTANA, D. et al. O poder persuasivo de anúncios publicitários do creme dental Colgate Total 12. Temática, Paraiba, v. 9, n. 6, 2013.

SCHÄFER, M. Mediated trust in science: concept, measurement and perspectives for the 'science of science communication'. JCOM, [s. l.], v. 15, n. 05, p. 1-7, 2016. https://doi.org/10.22323/2.15050302.

SCHMITZ, D. Será que o jovem só vê TV? A juventude nas pesquisas de recepção. In: JACKS, N. (org.). Meios e audiências II: a consolidação dos estudos de recepção no Brasil. Porto Alegre: Sulina, 2014. p. 31-72.

SECRETARIA NACIONAL DE CIENCIA, TECNOLOGIAY INNOVACION (SENACYT). V Encuesta de Percepción Social de la Ciencia y la Tecnología. Panamá: [s. n.], 2017. https://doi.org/10.22430/21457778.403.

SELLTIZ, C. et al. Métodos de pesquisa nas relações sociais. São Paulo: EPU, 1974.

SIQUEIRA, D. Ciência na televisão: mito ritual e espetáculo. São Paulo: Annablume, 1999.

SIQUEIRA, D. O cientista na animação televisiva: discurso, poder e representações sociais. Em questão, Porto Alegre, v. 12, n. 1, p. 131-148, jan./jun., 2006.

SOARES, G.; SCALFI, G. Adolescentes e o imaginário sobre cientistas: análise do teste "Desenhe um cientista" (DAST) aplicado com alunos do $2^{\circ}$ ano do Ensino Médio. In: CONGRESO IBEROAMERICANO DE CIENCIA, TECNOLOGÍA, INNOVACIÓN Y EDUCACIÓN, 2014, Buenos Aires. Anais [...]. Buenos Aires: [s. n.], 2014.

STEINKE, J. et al. Assessing Media Influences on Middle School-Aged Children's Perceptions of Women in Science Using the Draw-A-Scientist Test (DAST). Science Communication, Estados Unidos, p. 35-64. 2007. https://doi.org/10.1177/1075547007306508.

TOALDO, M.; MALCHER, M. Publicidad y cuestiones morales: provocaciones con jóvenes en el sur de Brasil. Chasqui. Revista Latinoamericana de Comunicación, Equador, n. 134, p. 201-219, 2017. https://doi. org/10.16921/chasqui.voi134.3011.

TORRES, H. La ciencia en la televisión nacional. Análisis de los comerciales de Televisión. 2012. 175f. Dissertação (Mestrado em Sociologia) - Universidad Nacional de Colombia, Bogotá, 2012

TRINDADE, E.; MOREIRA, R. Aspectos da recepção publicitária e das práticas de consumo em três famílias paulistanas. Revista ECO-Pós, Rio de Janeiro, v. 13, n. 1, 2010. https://doi.org/10.5841/extraprensa.v1i1E.44. 
WHITELEGG, E. et al. (In)visible Witnesses: Investigating gendered representations of scientists, technologists, engineers and mathematicians on UK children's television. UK Resource Centre for Women in Science, Engineering and Technology, Bradford, UK, 2008.

WURFF, R.; VERHOEVEN, P.; GADELLAA, Maite. Scientists and deliberativeness of European public television news. Journal of Science Communication, [s. l.], v. 12, n. 3, outono/inverno 2013. https://doi. org/10.22323/2.12030202.

\section{Vanessa Brasil de Carvalho}

Doutora pelo Programa de Educação, Gestão e Difusão em Biociências, da Universidade Federal do Rio de Janeiro (2018). Possui Mestrado em Comunicação, Cultura e Amazônia pela Universidade Federal do Pará (2013), onde também cursou Comunicação Social- Jornalismo (2010). Atualmente, é bolsista de pós-doutorado da Casa de Oswaldo Cruz (Fundação Oswaldo Cruz), no âmbito do Programa de Pós-Graduação em Divulgação da Ciência, Tecnologia e Saúde, e atua como colaboradora no Núcleo de Estudos de Divulgação Científica do Museu da Vida (Fiocruz).

\section{Luisa Massarani}

Doutora na Área de Gestão, Educação e Difusão em Biociências pela Universidade Federal do Rio de Janeiro (2001). Fez doutorado-sanduíche com bolsa da Capes no Department of Science and Technology Studies da University College London, pós-doutorado na University College London (2013), pós-doutorado na Oregon State University (2015-2016). Graduação em Comunicação Social pela Pontificia Universidade Católica do Rio de Janeiro (1987) e mestrado em Ciência da Informação pelo Instituto Brasileiro de Informação em Ciência e Tecnologia (1998),

\section{Endereço para correspondência}

Vanessa Brasil de Carvalho/ Luisa Massarani

Casa de Oswaldo Cruz

Avenida Brasil, 4365, Manguinhos

Rio de Janeiro, RJ, Brasil 